\title{
The relationship between serum cortisol, adrenaline, blood glucose and lipid profile of undergraduate students under examination stress.
}

\author{
Ignatius C Maduka ${ }^{1}$,Emeka E Neboh ${ }^{2}$, Silas A Ufelle
}

1. Nnamdi Azikiwe University Awka, Human Biochemistry

2. Department of Medical Biochemistry, College of Medicine, Enugu State, University of Science and Technology, Nigeria.

3. University of Nigeria, Medical Laboratory Sciences

\begin{abstract}
.
Background: Stress is an extremely adaptive phenomenon in human beings and cortisol is a known stress hormone. Examination has been described as a naturalistic stressor capable of affecting human health.

Objectives: To estimate the relationship between serum cortisol, adrenaline, fasting blood glucose (FBG) and lipid profile during examination stress.

Methods: Two hundred and eight (208) apparently-healthy undergraduate students (aged, $24 \pm 6$ years) were involved in the study. Exactly $5 \mathrm{mls}$ of venous blood was collected from each subject 1-3 hours before a major examination. A second assessment was done on the same students 3-4 weeks before any examination (control samples). Cortisol and adrenaline were assayed using ELISA techniques, FBG was assayed using enzymatic method while lipid parameters were assayed using standard enzymatic- spectrophotometric methods.

Results: There was statistically significant increase in serum cortisol, adrenaline, Total cholesterol, HDL-cholesterol and LDL-cholesterol levels in students under examination stress compared to the non examination period $(\mathrm{p}=0.001,0.013$, $0.0001,0.0001$ and 0.0001 , respectively). FBG showed no significant increase. There was also significant positive correlation $(\mathrm{r}=0.297, \mathrm{p}=0.032)$ between serum cortisol and TC/HDL ratio (cardiac risk factor) before examination stress but not during the stress period.

Conclusions: Significant positive correlation was observed between cortisol and TC/HDL ratio before examination stress.
\end{abstract}

Key words: academic examination, stressors, cortisol, lipid profile.

DOI: http://dx.doi.org/10.4314/ahs.v15i1.18

\section{Introduction}

Physical and psychological stresses can induce a wide range of immunological alterations in the cell mediated and humoral immunity ${ }^{1,2}$. Although the basic neurochemistry of the stress response is now well understood, much remains to be discovered about how the components of this system interact with one another, in the brain, and throughout the body ${ }^{3}$. Both negative and positive stressors can lead to stress. The intensity and duration of stress changes, depending on

\section{Corresponding author: \\ Neboh Emeka \\ Department of Medical Biochemistry, College of Medicine, Enugu State University of Science and Technology, Nigeria. \\ E.mail.emmyneboh@yahoo.com}

the circumstances and emotional condition of the person suffering from it and examples of stressors ranges from sensory input such as pain, to life experiences such as poverty. Besides releasing typical stress metabolites, characteristic enzymes and hormones, primary factors of psychological stress situations, possible reactions and recognizable symptomatic organic changes also show multi-factorial appearances ${ }^{1}$. Exposure to psychological stressors can modulate the primary antibody response and increased permanent stress levels can lead to pathological organ changes, psychological alterations as well as psychosomatic diseases ${ }^{4}$.

In humans, a range of stressful events have been associated with lowering the immune system functioning, including examinations, battle task, vigilance, sleep deprivation and divorce ${ }^{5}$. Academic examinations have often been used in stress research because they are predictable, standardized, and discrete examples of real-life stressors. They are associated with changes in the mental and physical health such as increasing anxiety, increasing negative mood and changes in the immune functioning ${ }^{5}$. 
Wile a few studies have found significant positive correlations between psychological and hormonal measures of stress, others have found no significant correlations between these measures, or even negative correlations between these measures ${ }^{6,7}$. Since serum cortisol has similar primary structure (cyclopentanoperhydrophenanthrene ring system) as steroids and lipids, and lipids are usually metabolized to release energy, there may be a possibility of examination stress affecting the lipid profile in the body. Any alteration in the plasma lipid which leads to increase in cardiac risk factor may ultimately predispose the student to risk

Academic examinations have been reported to also have a significant impact on the student's well-being We tested the hypothesis that examination stress may lead to increase in stress hormones cortisol and adrenaline and an alteration in plasma lipid profile and fasting blood glucose and that there may be a positive relationship between cortisol and the other parameters. The present study is therefore aimed at evaluating the nd fasting blood olucose (FBG) during academic examination stress in Nigerian undergraduate students. The findings from this study will highlight the possible need for continuous assessment of students which will help reduce risk associated. To the clinicians, the findings will enhance the understanding of the students plights and possible medical conditions in the management of students.

\section{Material and method}

Subjects

The subjects consist of 208 (132 males and 76 females) apparently healthy undergraduate students aged between 18 and 30 years. They were recruited from Medical laboratory science and Medical students from University of Nigeria, Enugu Campus and Enugu state University of Science and Technology respectively, after an informed consent. Approval was given by the ethics committee of the institution and questionnaire containing clear study protocol was administered to the students and only those who completed and returned the questionnaire were enrolled for the study. Subjects who enrolled but could not complete the protocol were dropped from the study.

Students were included in the study if they were: a) Undergraduate medical or medical laboratory students aged between 18 and 30 years, who are not on contraceptives or steroid therapy. b) Students living inside the normal students' hostel. c) Apparently healthy unmarried students not under any visible stress like surgery, illness, non-payment of school fees, abnormal menstruation, trauma etc d) Students likely to sit for a major professional examination for the first time within the next one year. In this study, Major examination for medical/ medical aboratory students is defined as the respective professional examinations, which if not passed by the student may lead to loss of a session, withdrawal or expulsion from course of study.

\section{Sample Collection $\&$ processing}

The study protocol involved collecting fasting blood sample from each participant by $9.00 \mathrm{am}$. The samples were collected from the same students on each of the following periods:

a) One-three hours before any major examination (e.g. first or final professional examination), and

b) Three-four weeks before any major examination (which served as control sample).

Subjects were made to relax before sample collection which was done with minimal stasis and pain. Samples consist of $5 \mathrm{mls}$ of venous blood collected aseptically from antecubital vein and dispensed into fluoride oxalate tube for blood sugar estimation and plain venoject ${ }^{\circledR}$ tube for other studies. The blood in the plain tube were transported to the lab in ice pack, centrifuged immediately using refrigerated centrifuge and an aliquot of the separated sera stored frozen $\left(-20^{\circ} \mathrm{C}\right)$ until analyzed within 48 hours, for cortisol and adrenaline levels. The rest were stored at $4^{0} \mathrm{C}$ for the estimation of lipid pro-

file within 48 hours. Both samples and reagents wete brought to room temperature before analysis.

Commercial control serum (QCA SERISCANN ${ }^{\circledR}$, Quimica Clinica Applicada. SA Spain) was included in each assay to evaluate the assay method and technique.

\section{Analytical Method:}

Blood glucose was analyzed using the enzymetic method of Trinder ${ }^{9}$

The method of Fossati and Prencipe ${ }^{10}$ and $\mathrm{Mc}-$ Gowan et $\mathrm{al}^{11}$ which involve the enzymatic hydrolysis of triglyceride to glycerol was employed in triglyceride estimation. The enzymatic colorimetric method by Allain et $\mathrm{al}^{12}$ was employed for cholesterol estimation. HDL- cholesterol was assayed using the method of Burnstein et al,

LDL-Cholesterol and VLDL-Cholesterol were calculat- ed from the results of total cholesterol, HDL-choles- Statistical analysis terol and triglycerides as recommended by Friedwald et $\mathrm{S}$ al ${ }^{14}$ and National Cholesterol Education Programme $e^{15}$. Serum cortisol was assayed by ELISA technique ${ }^{13}$, whereas adrenaline was estimated using quantitative sandwich immunoassay technique of Burtis et al., ${ }^{16}$ The results of cortisol and epinephrine were read-off directly from the respective standard curves.

Statistical analysis was performed with graph pad prism computer software and data was analyzed using students' $t$ test at 95 percent confidence limit with $\mathrm{P}<0.05$ considered as significant. The results were presented as mean and standard deviation (SD). Relationships becortisol and other parameters were determined using the Rank correlation analysis.

\section{Results}

Table 1 shows the demographic profile of the students.

Table 1: Demographic profile of the students studied

\begin{tabular}{|l|l|l|l|l|}
\hline & \multicolumn{2}{|c|}{ Before Exam } & \multicolumn{2}{c|}{ During Exam } \\
\hline Age (years) & Male & Female & Male & Female \\
\hline $18-21$ & $32(24.2 \%)$ & $20(26.3 \%)$ & $32(24.2 \%)$ & $20(26.3 \%)$ \\
\hline $22-25$ & $58(44 \%)$ & $34(44.7 \%)$ & $58(44 \%)$ & $34(44.7 \%)$ \\
\hline $26-30$ & $42(31.8 \%)$ & $22(29 \%)$ & $42(31.8 \%)$ & $22(29 \%)$ \\
\hline Level of study & & & & \\
\hline $300-400$ & $68(51.5 \%)$ & $40(53 \%)$ & $68(51.5 \%)$ & $40(53 \%)$ \\
\hline $500-600$ & $64(48.5 \%)$ & $36(47 \%)$ & $64(48.5 \%)$ & $36(47 \%)$ \\
\hline Religion & & & & \\
\hline Christians & $132(100 \%)$ & $76(100 \%)$ & $132(100 \%)$ & $76(100 \%)$ \\
\hline Moslems & $0(0 \%)$ & $0(0 \%)$ & $0(0 \%)$ & $0(0 \%)$ \\
\hline Foot note:
\end{tabular}

-400 level: Students in 3rd year and 4th year in the Medical School.

level: Students in 5th year and 6th year in Medical School

Table 2 shows the levels of serum cortisol, adrenaline, els of cortisol, adrenaline, total cholesterol, HDL-choFBG and serum lipid profile before and during academ- lesterol and LDL-cholesterol ( $\mathrm{P}=0.001,0.013,0.0001$ ic examination stress in the undergraduate students. 0.0001 and 0.0001 , respectively) during examination The results showed significantly increased serum lev- compared to the non-examination period (Table 2).

Table 2: FBG, cortisol, adrenaline and lipid profile levels of the students before and under examination tress.

\begin{tabular}{|lcccccc|}
\hline & Mean & SD & Mean & SD & T-value & P-value \\
\hline FBG (mmol/1) & 3.562 & $\mathbf{0 . 6 8 9}$ & 3.419 & $\mathbf{0 . 6 6 5}$ & $\mathbf{1 . 2 0 0}$ & $\mathbf{0 . 2 3 6}$ \\
Cortisol $(\mathrm{ng} / \mathrm{ml})$ & 78.808 & 27.530 & 94.039 & 25.477 & 3.454 & 0.001 \\
Adrenaline & 3.029 & 13.765 & 35.550 & 1.875 & 2.575 & $\mathbf{0 . 0 1 3}$ \\
T C (mmol/1) & 3.364 & $\mathbf{0 . 7 6 2}$ & 4.508 & $\mathbf{0 . 7 1 6}$ & 16.288 & $\mathbf{0 . 0 0 0 1}$ \\
HDL (mmol/1) & 1.046 & $\mathbf{0 . 2 7 5}$ & 1.356 & $\mathbf{0 . 3 7 0}$ & 5.410 & $\mathbf{0 . 0 0 0 1}$ \\
LDL (mmol/1) & 1.896 & $\mathbf{0 . 3 8 1}$ & 2.779 & $\mathbf{0 . 6 4 4}$ & 10.066 & $\mathbf{0 . 0 0 0 1}$ \\
VLDL (mmol/1) & $\mathbf{0 . 3 8 1}$ & $\mathbf{0 . 1 1 4}$ & $\mathbf{0 . 3 7 1}$ & $\mathbf{0 . 1 1 9}$ & $\mathbf{0 . 5 6 6}$ & $\mathbf{0 . 5 7 4}$ \\
Triglyceride & $\mathbf{0 . 8 1 7}$ & $\mathbf{0 . 2 2 1}$ & $\mathbf{0 . 8 0 4}$ & $\mathbf{0 . 2 7 2}$ & $\mathbf{0 . 3 7 9}$ & $\mathbf{0 . 7 0 6}$ \\
TC/HDL Ratio & 3.454 & 1.287 & 3.473 & $\mathbf{0 . 7 2 3}$ & $\mathbf{0 . 0 9 7}$ & $\mathbf{0 . 9 2 3}$ \\
\hline
\end{tabular}

Legend
FBG $\rightarrow$ Fasting blood glucose

$\mathrm{TC} \rightarrow$ Total cholesterol

$\underset{\text { HDL } \rightarrow \quad \text { High density lipoprotein }}{\text { Low density lipoprotein }}$

VLDL $\rightarrow$ Very low density lipoprotein 
Table 3 showed the relationship between serum cortisol and adrenaline, FBG, and lipid profile before and under examination stress. The table showed significant positive correlation $(r=0.297, p=0.032)$ between serum cortisol and TC/HDL-cholesterol ratio (cardiac risk factor) before examination stress, but not during examination stress. There was no statistical difference in fasting blood glucose before and during examination stress.

Table 3: The relationship between serum cortisol and fbg, adrenaline and lipid profile values before and under examination stress

$(n=208)$.

\begin{tabular}{|l|l|l|l|l|}
\hline & \multicolumn{2}{|c|}{ BEFORE } & \multicolumn{2}{c|}{ DURING } \\
\hline & r-value & \multicolumn{1}{|c|}{ p-value } & \multicolumn{1}{c|}{ r-value } & p-value \\
\hline FBG(mmol/l) & 0.049 & 0.731 & 0.252 & 0.072 \\
\hline Adrenaline(ng/ml $)$ & 0.020 & 0.888 & 0.229 & 0.102 \\
\hline TC(mmol/l) & 0.088 & 0.537 & 0.036 & 0.798 \\
\hline HDL(mmol/l) & 0.233 & 0.096 & -0.094 & 0.508 \\
\hline LDL(mmol/l) & 0.198 & 0.160 & 0.104 & 0.463 \\
\hline VLDL(mmol/l) & 0.123 & 0.384 & -0.046 & 0.746 \\
\hline TG(mmol/l) & 0.139 & 0.327 & -0.086 & 0.542 \\
\hline TC/HDL & 0.297 & 0.032 & 0.150 & 0.289 \\
\hline
\end{tabular}

Legend

FBG $\rightarrow$ Fasting blood glucose

$\mathrm{TC} \rightarrow$ Total cholesterol

$\mathrm{HDL} \rightarrow$ High density lipopetein

$\mathrm{HDL} \rightarrow$ High density lipoprotein

$\mathrm{VLDL} \rightarrow$ Very low density lipoprotein

\section{Discussion} In the present study, we tested the hypothesis that ex- significant positive correlation $(r=0.297, \mathrm{p}=0.032)$ amination stress may lead to increase in stress hormones between serum cortisol and TC/HDL- cholesterol ratio cortisol and adrenaline and an alteration in plasma lipid (cardiac risk factor) before examination stress, but not a positive relationship between cortisol and the other were exposed to stress and abnormal lipid profile even parameters. before the examination period, probably due to the thought of the impending examination which exposes The results showed significantly increased serum levels the students to stress before the actual examination. of cortisol, adrenaline, total cholesterol, HDL-cholesterol and LDL-cholesterol $(\mathrm{P}=0.001,0.013,0.0001$, The relationship obtained may actually not be connect0.0001 and 0.0001 , respectively) during examination ed to the examination since it did not manifest during compared to the non-examination period (Table 2). the examination period. No relationship was however This implies an increase in the stress hormones and li- observed between cortisol and the other parameters pids as a result of the ongoing examination. There was studied both before and during examination stress. This no statistical difference in fasting blood glucose before and during examination stress.

We also tested the hypothesis that there may be a positive correlation between cortisol and the other pationship between high stress cortisol and lipid profile levels reported by Roy et $\mathrm{al}^{17}$

The increase in the stress hormones observed may be as a result of stimulation of the ACTH secretion by the stress stimuli which stimulated the synthesis of adrenaline and cortisol precursors ${ }^{16}$. In response to a stressor, neurons with cell bodies in the paraventricula nuclei of the hypothalamus secrete corticotrophin releasing hormone (CRH) and arginine-vasopressin (AVP) into the hypophyseal portal system ${ }^{18,19}$. The CRH through the HPA then activates the pituitary and adrenal glands. These interactions can lead to immune system changes leading to increase in vulnerability to infection and increase in potential for an outbreak of certain diseases such as psoriasis ${ }^{5}$. Over secretion of stress hormones affect the brain where memories are processed and stored ${ }^{20}$, and might cause hormonal and metabolic changes that contribute to heart disease and other health problems ${ }^{21}$

Based on our hypothesis, the present study showed that the stress hormones adrenaline and cortisol secretions, TC, LDL and HDL were raised by examinatio stress. Since over secretion of stress hormones affects the brain where memories are processed and stored, ${ }^{20}$ the findings of this study implies that over stressed students may develop memory problems which will affect the outcome of their examination performance. The examinations studies may not actually be a true test of knowledge of these set of stressed students. The excessive response to stress observed in this study may be as a result of fear associated with the examinatior This may also be linked to the warning and knowledge of the fate of the past students who did not excel in the previous similar examinations. Some were expelled, some were asked to withdraw or change courses while others were made to loose one semester or one full session with the attendant additional school fees. It may also be noted that some students were never ready for the respective examinations as a result of not being serious with their studies until examination date is announced. Such students study under duress and severe stress, and are always afraid of examinations.

The result of this study supports the reports of Quresh et $\mathrm{al}^{22}$ and Viner $^{23}$ who reported an increase in visceral fat due to stress, and that of Glavas and Weinberg ${ }^{20}$ who reported an over secretion of cortisol as a result of stressors. The lack of significant positive cc between elevations in cortisol and elevations in psychological stress during the examination period was in agreement with the study by Weekes et al., ${ }^{7}$ who reported no significant correlations in cortisol and elevation psychological stress measures. However, the causal petween increase in stress hormone and serum lipid levels could not be established by the present study although they have same precursor skeletal structure.

\section{Conclusion}

The present study showed significant increase in cortisol, adrenaline, TC, HDL and LDL but no correlation between cortisol and the other parameters during examination stress. There was also significant positive correlation between cortisol and TC/HDL ratio (cardiac risk factor) before examination stress. Although serum cortisol has similar primary structure (cyclopentanoperhydrophenanthrene ring system) as steroids and lipids, the abolition of normal physiological control mechanism observed in examination stress did not re-

late to the serum concentration of these parameters. This may be as a result of physiological compensatory mechanisms. To the teachers, the findings from this study highlights the need for continuous assessment of students which helps reduce risk associated with single exam that may not actually be a true test of knowledge for a high stress-prone student. To the, clinicians, this calls for understanding of the students' plights and possible medical conditions in the management of students. To the students, the findings will help them manage stress better especially since they will no longer be udged during exams alone, as the outcome may actually be affected by stress.

\section{References}

Schore A (2003) Affect Regulation \& the Repair of the Self. New York: W.W. Norton. ISBN 0393704076

2. Pades JA, Homar AC (2006) Student stress in clinical practice for nurses. Rev Enferm. 29: 19-24

3. Keil RMK (2004) Coping and stress: a conceptual analysis. J Adv Nursing, 45: 659-665

4. Moraska A, Campisi J, Nguyen KT, Maier SF, Watkins LR, Fleshner M (2002) Elevated IL-1 beta contributes to antibody suppression produced by stress. $J$ Appl Physiol 93: 207-215

5. Shamsdin SA, Anvar M, Mehrabani D (2009) The effect of exam stress on IL-6, cortisol, CRP and IgE levels, Iranian Red Crescent Medical Journal 12: 484-488

6. Roy MP (2004) Patterns of cortisol reactivity to laboratory stress. Hormones Behav 46:618-627. 
ical inducer of cortisol and physiological responses to stress in undergraduate students. Stress 9:4: 199-206.

8. Loft P, Thomas MG, Petrie KJ, Booth RJ, Miles J, Vedhara K (2007) Examination stress results in altered cardiovascular responses to acute challenge and lower cortisol. Psychoneuroendocrinology 32: $367-$ 75

9. Trinder P (1969) Determination of blood glucose using an oxidase peroxidase system with a non carcinogenic chromogen. J. Clinical Chemistry Pathology 22: 158-161

10. Fossati P, Prencipe L (1982) Serum triglycerides determined colorimetrically with an enzyme that produces hydrogen peroxide. Clinical Chemistry 28: 2077-2080 11. McGowan MW, Artiss JD, strandbergh DR, Za P (1983) Peroxidase-coupled method for the colorimetric determination of serum triglycerides. Clinical Chemistry 29:538-542

12. Allain CC, Poon LS, Chan CSG, Richmond W, FU PC (1974) Enzymatic determination of total serum cholesterol. Clinical Chemistry 20: 470-475

13. Burnstein M, Scholnick HR, Morfin R (1980) Rapid method for the isolation of lipoproteins from human serum by precipitation with polyanions. Scand J. Clinical Lab Invest 40: 583-595

14. Friedewald W'T, Levey RT, Fredrick DS (1972) Estimation of concentration of LDL-Cholesterol without the use of preparative ultracentrifuge. Clinical Chemistry 18:499 - 509

15. National Cholesterol Education Programme, NCEP
(1993) Summary of the second Report of the National Cholesterol Education Programme (NCEP) expert Panel on detection and treatment of high blood cholesterol in adults. JAMA 269: 3015-3023

16. Burtis C, Ashwood AR, Aldrich JE (2001) Endocrine hormones: In: Tietz Fundamentals of Clinical Chemistry, 4th (edn); W.B. Saunders \& Co: pp 780-794 17. Roy MP, Kirschbaum C, Streptoe A (2001) Psychological, cardiovascular and metabolic correlates of individual differences in cortisol stress recovery in young men. Psychoneuroendocrinology 26: 375-391

18. Sabyasachi S (2007) Medical Physiology. Thieme Publishing Group. pp. 536-546.

19. Tsigos C, Chrousos GP (2002) Hypothalamic-pituitary-adrenal axis, neuroendocrine factors, and stress. Journal of Psychosomatic Research 53: 865-871

20. Glavas MM, Weinberg J (2006) Stress, Alcohol Consumption, and the Hypothalamic-Pituitary-Adrenal Axis. In Yehuda S, Mostofsky DI (eds), Nutrients, Stress, and Medical Disorders. Ottowa, NJ: Human Press, pp. 165-183

21. Sauro MD, Jorgensen RS, Pedlow CT (2003) Stress, glucocorticoids and memory: a meta-analytic review. Stress 6: 235-245

22. Qureshi GM, Seehar GM, Zardari MK, Pirzado ZA, Abbasi SA (2009) Study of blood lipids, cortisol and haemodynamic variations under stress in male adults. $J$ Ayab Med Coll Abbottabab 21: 158-161

23. Viner, R. (1999): Putting Stress in Life: Hans Selye and the Making of Stress Theory. Social Studies of Science 29: 391-410 